\title{
PENETAPAN KADAR FENOLIK TOTAL EKSTRAK ETANOL 70\% DAN FRAKSI ETIL ASETAT DAUN BAWANG DAYAK (Eleutherine palmifolia (L.) Merr) DENGAN METODE SPEKTROFOMETRI UV-VIS
}

\author{
Eka Kumalasari*', Nazulla Mudjib Nararia, Siska Musiam \\ Sekolah Tinggi Ilmu Kesehatan ISFI Banjarmasin \\ *: ekakumalasari260989@gmail.com
}

\begin{abstract}
ABSTRAK
Bawang dayak (Eleutherine palmifolia (L.) Merr.) digunakan oleh masyarakat didaerah Kalimantan Tengah sebagai pengobatan secara tradisional dengan memanfatkan bagian umbi bawang dayak sedangkan bagian daunnya jarang dimanfaatkan, bagian daun bawang dayak juga memiliki potensi secara alami bermanfaat sebagai obat tardisional karena mengandung senyawa fenol. Senyawa fenol bermanfaat sebagai antioksidan, anti inflamasi, hemostatik dan antitumor. Tujuan dari penelitian ini adalah mengetahui kandungan senyawa kimia fenolik pada fraksi etil asetat dan ekstrak etanol $70 \%$ daun bawang dayak dan mengetahui kadar fenolik total yang terkandung didalamnya

Sampel pada penelitian ini adalah daun bawang dayak yang didapatkan dari Palangkaraya, Kalimantan Tengah. Ekstraksi daun bawang dayak menggunakan metode maserasi. Fraksi ekstrak dibuat dengan metode ekstraksi cair - cair dengan pelarut etil asetat. Metode penetapan kadar yang digunakan adalah Spektrofotometri Uv-Vis dengan pereaksi Folin ciocalteau. Hasil penelitian ini menunjukkan bahwa ekstrak etanol $70 \%$ dan fraksi etil asetat daun bawang dayak mengandung senyawa Fenolik. Kadar fenolik pada penelitian fraksi etil asetat daun bawang dayak adalah 10,61\% $\%$ 0,0019 dikatakan lebih besar dari kadar ekstrak etanol $70 \%$ daun bawang dayak adalah 2,23\% $\pm 0,0002$.
\end{abstract}

Kata kunci: Daun Bawang Dayak, (Eleutherine palmifolia L. Merr.), Fenolik, Spektrofotometri UV-Vis.

\begin{abstract}
Dayak onion (Eleutherine palmifolia (L.) Merr). Is used by the people in Central Kalimantan as a traditional treatment by utilizing onion dayak tubers while the leaves are rarely used, the part of dayak onion leaves also have the potential to naturally be useful as traditional medicine because they contain compounds phenol. Phenol compounds are useful as antioxidants, anti-inflammatory, hemostatic and antitumor. The purpose of this study was to determine the content of phenolic chemical compounds in ethyl acetate fraction and $70 \%$ ethanol extract of dayak onion leaves and find out the total phenolic content contained.

The sample in this study is Dayak onion leaves from Palangkaraya, Central Kalimantan. Extraction of onion dayak leaves using maceration method. Fraction extract was made by liquid-liquid extraction method with ethyl acetate solvent. The level determination method used was Uv-Vis Spectrophotometry with Folin ciocalteau reagent. The results of this study indicate that from $70 \%$ ethanol extract and dayak onion leaves ethyl acetate fraction is containing phenolic compounds. Phenolic levels in this study obtained total levels of dayak onion leaves
\end{abstract}


ethyl acetate fraction was $10.61 \% \pm 0.0019$ said to be greater than the $70 \%$ ethanol extract content of dayak onion leaves was $2.23 \% \pm 0.0002$.

Keywords: Eleutherine palmifolia L. Merr), Phenolic, UV-Vis Spectrophotometry.

\section{PENDAHULUAN}

Bawang Dayak di Indonesia lebih dikenal, dengan bawang hantu, bawang sabrang dan bawang arab. Masyarakat di berbagai daerah di Kalimantan Tengah umumnya menggunakan bagian umbi Bawang Dayak dalam pengobatan tumor secara tradisional, sedangkan bagian daunnya jarang dimanfaatkan sebagai obat tradisional ${ }^{1}$.

Penelitian sebelumnya yang telah dilakukan Pratiwi,dkk menjelaskan bahwa ekstrak etanol daun bawang dayak mengandung senyawa alkaloid, flavonoid, saponin, fenol, triterfenoid dan steroid. Dari penelitian diperoleh kadar antioksidan fenolik ekstrak etanol $70 \%$ daun bawang dayak positif memiliki aktivitas antioksidan menggunakan pereaksi DPPH 0,2\%, Nilai IC $_{50}$ ekstrak etanol $70 \%$ daun bawang dayak adalah sebesar $31,97437 \mu \mathrm{g} / \mathrm{mL}$ dengan menggunakan metode Spektrofotometri UV-Vis ${ }^{2}$.

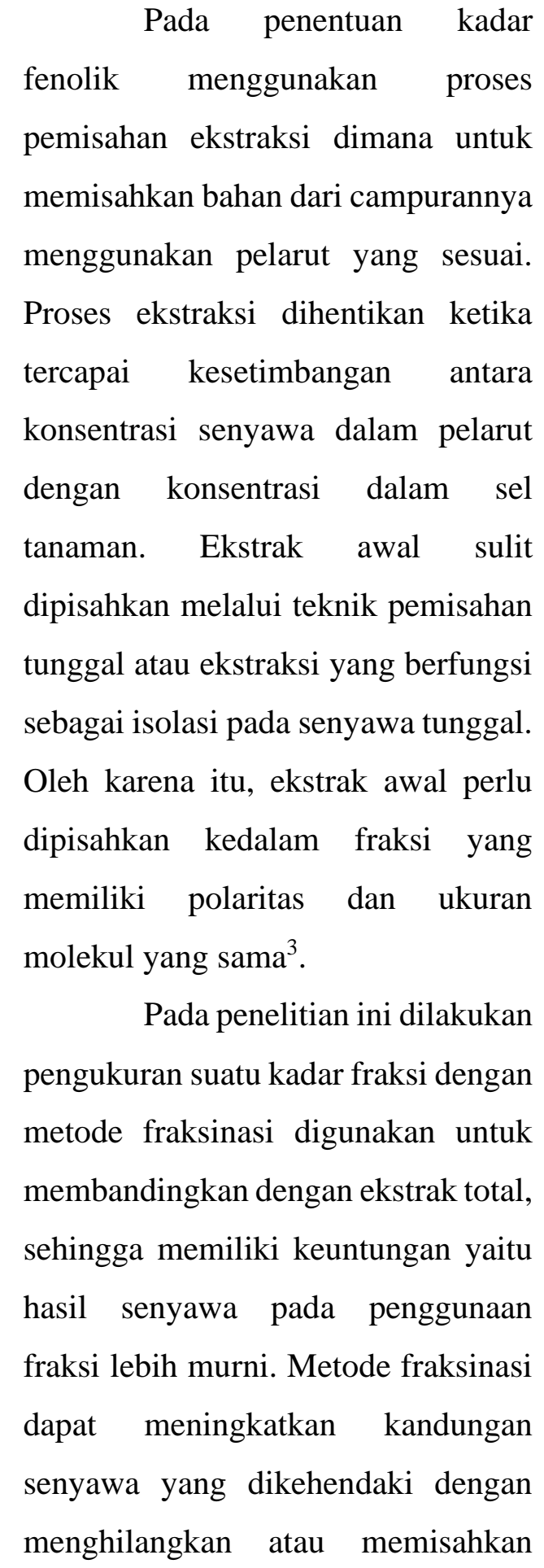


senyawa yang tidak dikehendaki, sehingga diperoleh fraksi yang lebih murni $^{4}$.

Penelitian tentang kadar fenolik total pada daun bawang dayak dan fraksi etil asetat ekstrak daun tersebut belum pernah dilakukan sebelumnya sehingga peneliti tertarik ingin mengetahui seberapa banyak kandungan senyawa kimia Fenolik dalam Daun Bawang Dayak. Diharapkan dari hasil penelitian ini dapat menjelaskan secara ilmiah manfaat alami dari daun bawang dayak serta dapat menjadi dasar diadakannya penelitian lanjutan tentang potensi daun bawang dayak sebagai obat tradisional.

\section{METODE}

Daun Bawang Dayak yang didapatkan dari Palangkaraya, Kalimantan Tengah, Sampel pada penelitian ini adalah Daun Bawang Dayak yang memiliki kriteria sebagai berikut: Daun bawang dayak yang berwarna hijau, Daun bawang dayak yang tidak busuk, Daun bawang dayak yang tidak berlubang.

\section{Pembuatan ekstrak}

Pembuatan simplisia dimulai dengan sortasi basah, kemudian daun bawang dayak dipotong kecil-kecil lalu dikeringkan menggunakan oven dengan suhu $50^{\circ} \mathrm{C}$. Setelah itu dilakukan sortasi kering. Simplisia diekstraksi menggunakan pelarut etanol 70\% sampai seluruh serbuk terendam sempurna. Pergantian pelarut pada maserasi dilakukan setiap 24 jam sekali selama 3 hari hingga diperoleh filtrat. Filtrat daun bawang dayak dipisahkan melalui proses penyaringan dengan corong buchner. Kemudian filtrat di rotary evaporator dengan suhu $50^{\circ} \mathrm{C}$. Hasil yang diperoleh berupa ekstrak cair. Kemudian ekstrak dipekatkan dengan water bath pada suhu $50^{\circ} \mathrm{C}$ sampai diperoleh ekstrak kental

\section{Pembuatan Fraksinasi}

Proses fraksinasi dilakukan dengan cara hasil ekstrak daun bawang Dayak digerus sampai halus, disuspensikan ke dalam pelarut etanol dan dihomogenkan menggunakan Vortex selama 10 menit. Suspensi disaring menggunakan kertas saring, Hasil filtrat pada kertas saring lalu dilarutkan dalam pelarut etil asetat, 
kemudian dihomogenkan dengan vortex selama 10 menit. Larutan dipartisi dengan menambahkan akuades, selanjutnya dikocok dalam labu pemisah dan didiamkan selama 30-60 menit hingga terdapat dua lapisan (lapisan etil asetat di bagian atas dan lapisan akuades di bagian bawah). Kedua lapisan yang terbentuk kemudian dipisahkan ${ }^{5}$.

Proses fraksi etil asetat dapat juga dilakukan dengan cara ekstrak etanol dengan berat sekitar $100 \mathrm{~g}$ kemudian dilakukan partisi menggunakan pelarut dengan tingkat kepolaran yang berbeda. Pertama menggunakan pelarut n-heksana, ekstrak etanol kemudian dilakukan partisi kembali dengan pelarut etil asetat dan diperoleh fraksi etil asetat. Fraksi etil asetat yang diperoleh, selanjutnya dipekatkan menggunakan rotary evaporator dan digunakan untuk tahap uji aktivitas antioksidan ${ }^{6}$.

\section{Penentuan Senyawa Fenolik Total}

a. Penentuan Operating Time

Larutan asam galat

dengan konsentrasi dipipet $500 \mu \mathrm{g} / \mathrm{ml}$ dipipet $0,30 \mathrm{ml}$, ditambah $1,50 \mathrm{ml}$ reagen Folin-Ciocalteau yang sebelumnya telah diencerkan 10 kalinya dan dikocok. Didiamkan selama 3 menit, kemudian ditambah 1,20 ml larutan $\mathrm{Na}_{2} \mathrm{CO}_{3} 7,5 \%$ dan ad kan $10 \mathrm{ml}$ akuades dikocok sampai homogen, kemudian diamati absorbansinya selama waktu minimal 3 kali pengulangan pada waktu 0-90 menit sampai didapat waktu yang stabil dan maksimal pada spektrofotometri visible dengan panjang gelombang asam galat yaitu $765 \mathrm{~nm}$.

b. Penentuan Panjang Gelombang Absorbansi Maksimum

Larutan asam galat dengan konsentrasi $500 \mu \mathrm{g} / \mathrm{ml}$ dipipet $0,30 \mathrm{ml}$, ditambah 1,50 $\mathrm{ml}$ reagen Folin Ciocalteau yang sebelumnya telah diencerkan 10 kalinya dan dikocok. Didiamkan selama 3 menit, kemudian ditambah 1,20 ml larutan $\mathrm{Na}_{2} \mathrm{CO}_{3} 7,5 \%$ dan ad kan $10 \mathrm{ml}$ akuades dikocok sampai homogen, kemudian didiamkan pada suhu kamar selama waktu 
operating time yang telah didapat pada percobaan, kemudian diamati absorbansinya pada panjang gelombang spektrofotometri visible asam galat $600-850 \mathrm{~nm}$ pada hasil percobaan.

c. Pembuatan kurva baku asam galat dengan reagen FolinCiocalteau

Sebanyak $500 \mu \mathrm{g} / \mathrm{ml}$ larutan asam galat dengan konsentrasi 5, 10, 15, 20 dan $25 \mu \mathrm{g} / \mathrm{ml}$ masing-masing dipipet $0,30 \quad \mathrm{ml}$ dan ditambahkan $1,50 \mathrm{ml}$ reagen Folin-Ciocalteau yang sebelumnya telah diencerkan 10 kalinya dan dikocok. Diamkan selama 3 menit, kemudian ditambah 1,20 ml larutan $\mathrm{Na}_{2} \mathrm{CO}_{3} 7,5 \%$ dan ad kan 10 ml akuades dikocok sampai homogen. Didiamkan selama operating time yang telah didiperoleh pada percobaan pada suhu kamar sebagai waktu tunggu untuk mencapai nilai adsorbansi yang maksimal. Absorbansi diukur pada panjang gelombang serapan maksimumnya, kemudian dibuat kurva regresi hubungan antara konsentrasi asam galat ( $\mu \mathrm{g} / \mathrm{ml})$ dengan absorbansi.

d. Penetapan kadar fenolik total dengan metode FolinCiocalteau 10,0 mg ekstrak daun Bawang Dayak kemudian dilarutkan sampai $10,0 \mathrm{ml}$ etanol dan dihomogenkan. Dipipet 0,30 ml larutan ekstrak daun bawang dayak dan ditambahkan 1,50 $\mathrm{ml}$ reagen Folin-Ciocalteau yang sebelumnya telah diencerkan 10 kalinya dan kocok. Didiamkan selama 3 menit kemudian ditambahkan 1,20 ml larutan $\mathrm{Na}_{2} \mathrm{CO}_{3} \quad 7,5 \%$ kedalam campuran, didiamkan larutan selama operating time pada suhu kamar. Absorbansi diukur dengan spekrofotometer UVVis pada panjang gelombang absorbansi maksimumnya yang akan memberikan komplek biru. Lakukan 3 kali pengulangan sehingga kadar 
fenol yang diperoleh hasilnya didapat sebagai mg ekuivalen asam galat/g sampel ${ }^{7}$.

\section{HASIL}

Bobot total ekstrak yang didapat sebanyak 186,63 gram dengan rendemen sebesar 20,73\%. Ekstrak yang didapatkan berwarna coklat, berbau khas dan terasa pahit.

Analisis kadar fenolik pada ekstrak Daun Bawang Dayak dilakukan dengan menggunakan metode spektrofotometri Uv-Vis dengan standar baku Asam Galat dengan Metode Folin ciocalteau. Sebagai larutan standar atau pembanding digunakan asam galat yang merupakan salah satu fenolik alami dan stabil. Asam galat menjadi pilihan sebagai standar ketersediaan substansi yang stabil dan murni. Metode ini adalah metode yang paling umum untuk menentukan kandungan fenolik total pada pada tanaman dikarenakan teknik ini pengerjaanya lebih sederhana dan sebagai reagen Folin ciocalteau dapat bereaksi dengan folin membentuk larutan yang dapat diukur absorbansinya.
Penetapan Kadar menggunakan penambahan pereaksi $\mathrm{Na}_{2} \mathrm{CO}_{3} \quad 75 \%$ dan reagen Folin ciocalteau dimana reaksi yang terjadi adalah reaksi reduksi-oksidasi yaitu Senyawa fenolik mereduksi fosfomolibdat fosfotungstat dalam reagen folin ciocalteau membentuk molybdenum yang berwarna biru ${ }^{6}$. Adapun Reaksi yang terjadi pada senyawa fenol dengan reagen Folin membentuk senyawa kompleks yang stabil berwarna biru. Semakin besar konsentrasi senyawa fenolik maka semakin banyak ion fenolat yang akan mereduksi asam heteropoli fosfomolibdat-fosfotungstat menjadi kompleks molibdenum-tungsten sehingga warna biru yang dihasilkan semakin pekat ${ }^{7}$.

Hasil penetapan Operating Time diperoleh jika pengukuran yang stabil pada menit ke-1 dengan absorbansi 0,566. Hasil pencarian Panjang gelombang maksimum diperoleh pada Panjang gelombang $766 \mathrm{~nm}$ dengan menggunakan konsentrasi 15 ppm dengan nilai absorbansi 0,624 A dimana merupakan nilai absorbansi maksimum atau tertinggi. 
Pada penelitian ini sampel dan pelarut yang digunakan berbedabeda sehingga hasilnya berbeda dengan Panjang gelombang maksimal teoritis asam galat adalah $765 \mathrm{~nm}$.
- $0,8^{3}$. Setelah memperoleh nilai absorbansi dari larutan seri kadar asam galat, maka dapat dibuat persamaan garis yang dapat dilihat pada gambar 1

Absorbansi dikatakan baik apabila memasuki rentang antara 0,2

Tabel 1 Hasil Absorbansi larutan seri kadar Asam Galat

\begin{tabular}{|c|c|}
\hline Konsentrasi (ppm) & Absorbansi \\
\hline 5 & 0,295 \\
\hline 10 & 0,380 \\
\hline 15 & 0,463 \\
\hline 20 & 0,556 \\
\hline 25 & 0,688 \\
\hline
\end{tabular}

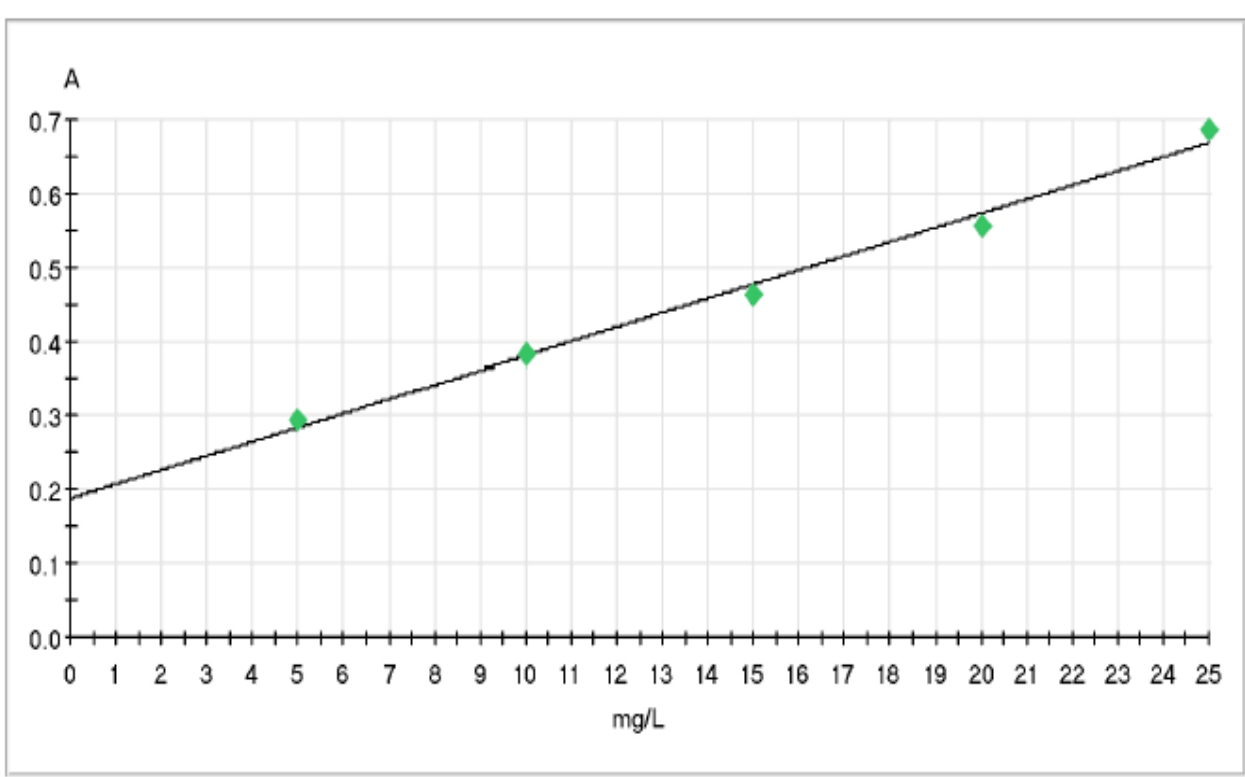

Curve parameters: $y=0.019216 x+0.18826$

Residual error: 0.0176 Correlation coefficient: 0.99501

Date: 6/27/2019 12:50:24 PM Autozero 6/27/2019 12:50:04 PM

Gambar 1 Regresi Linier Kurva Baku Asam Galat 
Berdasarkan gambar 1. 7,5\% kedalam campuran, larutan didapatkan regresi linear dengan $\mathrm{Na}_{2} \mathrm{CO}_{3} \quad 7,5 \%$ berfungsi membuat persamaan $\mathrm{y}=\mathrm{bx}+\mathrm{a}$ yaitu $\mathrm{Y}=$ $0,019216 X+0,18826$ dengan nilai suasana basa agar terjadi disosiasi proton, pada senyawa fenolik menjadi koefisien korelasi (r) sebesar 0,99501.

Pengukuran kadar sampel dilakukan dengan cara menimbang $10,0 \mathrm{mg}$ ekstrak etanol $70 \%$ dan fraksi etil asetat masing - masing sebanyak 3 kali replikasi kemudian dilarutkan dalam $10 \mathrm{ml}$ etanol dan aquadest dengan perbandingan 1:1 sehingga didapatkan 1000 ppm. Dipipet $1 \mathrm{ml}$ dari larutan tersebut dan dimasukkan ke dalam labu ukur 10 ml, di tambahkan etanol sampai tanda batas sehingga diperoleh konsentrasi 100 ppm. Dari 100 ppm dipipet 0,3 ml larutan ekstrak 100 ppm lalu masukkan kedalam tabung reaksi dan ditambahkan 1,50 $\mathrm{ml}$ reagen FolinCiocalteau yang sebelumnya telah diencerkan 10 kalinya dan kocok. Reagen Folin-Ciocalteau berfungsi membentuk larutan berwarna yang dapat diukur absorbansinya kemudian didiamkan selama 3 menit kemudian ditambahkan 1,20 ml larutan $\mathrm{Na}_{2} \mathrm{CO}_{3}$ ion fenolat. Lalu, diamkan larutan selama waktu Operating time yang telah didapat pada suhu kamar agar pada saat pembacaan absorbansi didapatkan absorbansi yang maksimal. Absorbansi diukur dengan spekrofotometer UV-Vis pada panjang gelombang $766 \mathrm{~nm}^{7}$.

Penetapan kadar fenolik total ekstrak etanol $70 \%$ dan fraksi etil asetat dilakukan dengan 3 kali pengulangan untuk mendapatkan keakuratan data dan didapatkan hasil ${ }^{8}$. Nilai absorbansi yang didapat dari spektrofotometri UV-Visible kemudian dihitung kadar fenolik total yang terkandung dalam ekstrak dan fraksi dengan menggunakan persamaan garis yang diperoleh dari kurva baku. 
Tabel 2 Hasil Perhitungan Kadar

\begin{tabular}{|c|c|c|c|c|c|}
\hline & $\begin{array}{l}\text { Konsentrasi } \\
\quad(\text { ppm })\end{array}$ & $\begin{array}{c}\text { Nilai } \\
\text { Adsorbansi } \\
\text { (A) }\end{array}$ & $\mathbf{x}(\mathbf{m g} / \mathbf{m l})$ & $\begin{array}{l}\text { Kadar } \\
(\% \mathbf{b} / \mathbf{b})\end{array}$ & $\begin{array}{c}\text { Rata-rata kadar }(\% \mathrm{~b} / \mathrm{b}) \\
\pm \text { SD }\end{array}$ \\
\hline \multirow{3}{*}{ Fraksi Etil Asetat } & 100 & 0,379 & 9,926 & 9,926 & \multirow{3}{*}{$10,61 \% \pm 0,0019$} \\
\hline & 100 & 0,363 & 9,093 & 9,093 & \\
\hline & 100 & 0,435 & 12,840 & 12,840 & \\
\hline \multirow{3}{*}{$\begin{array}{c}\text { Ekstrak Etanol } \\
\mathbf{7 0 \%}\end{array}$} & 200 & 0,271 & 4,253 & 2,126 & \multirow{3}{*}{$2,23 \% \pm 0,0002$} \\
\hline & 200 & 0,274 & 4,461 & 2,230 & \\
\hline & 200 & 0,279 & 4,722 & 2,361 & \\
\hline
\end{tabular}

Berdasarkan tabel diatas maka di dapat nilai standar deviasi (SD) yang merupakan akar jumlah kuadrat deviasi pada masing-masing hasil penetapan terhadap mean dibagi dengan derajat kebebasan (degrees of freedom). Standar deviasi digunakan sebagai pembanding ketepatan suatu hasil, dikatakan semakin kecil nilai Standar Deviasi (SD) dari serangkaian pengukuran, maka metode yang dilakukan semakin tepat apabila tidak lebih dari 5\%. Dari hasil perhitungan kadar fenolik total ekstrak dan fraksi dapat disimpulkan hasil yang diperoleh memiliki nilai SD kurang dari $5 \%$ dari hasil kadar rata-rata fenolik ekstrak etanol $70 \%$ didapat nilai $2,23 \% \pm 0,0002$ dan hasil kadar rata-rata pada fraksi etil asetat lebih besar dengan nilai $10,61 \% \pm 0,0019$.

Dikatakan kadar konsentrasi pada fraksi etil asetat yaitu 100 ppm didapat hasil lebih murni mengandung fenolik dikarenakan etil asetat spesifik untuk menarik senyawa fenol daripada kadar konsentrasi ekstrak yaitu 200 ppm dimana ekstrak memiliki banyak komponen yang terkandung didalamnya sehingga perlu konsentrasi yang lebih tinggi untuk mendeteksi kadar fenol didalamnya. Jadi, Semakin besar kadar fenolik pada fraksi maka besar pula manfaat yang terkandung didalamnya. Berdasarkan hal itu fraksi ekstrak 
daun bawang dayak dapat dikembangkan menjadi sediaan obat untuk terapi tambahan atau pencegahan suatu penyakit.

\section{KESIMPULAN}

1. Ekstrak etanol $70 \%$ dan fraksi etil asetat daun bawang dayak mengandung senyawa fenolik.

2. Kadar fenolik total Fraksi etil asetat daun bawang dayak adalah $10,61 \% \pm 0,0019$ lebih besar dari Kadar fenolik total Ekstrak etanol $70 \%$ daun bawang dayak yaitu $2,23 \% \pm 0,0002$

\section{DAFTAR PUSTAKA}

1. Al idrus, H.R. dkk. 2014. Uji Aktivitas Antioksidan Eektrak Etanol Daun Bawang Mekah (Eleutherine Americana Merr.) Terhadap Gambaran Histopatologi Paru Tikus (Rattus Norvegicus) Wistar Jantan Pasca Paparan Asap Rokok. Makasar: Jurnal Fitofarmaka Indonesia, (Online), 1(2): 51-60, (http://jurnal. farmasi.umi.ac.id) diakses 15 Maret 2017.

2. Pratiwi, D., Wahdaningsih, S., Isnindar. 2013.The Test of Antioxidant Activity From Bawang Mekah Leaves (Eleutherine americana Merr.) Using DPPH (2,2- Diphenyl-1Picrylhydrazyl) Method, Traditional Medicine Journal, 18(1), pp. 9-16.
3. Mukhriani., Nonci, F.Y., Munawarah, S. 2015. Analisis Kadar Flavonoid Total Pada Ekstrak Daun Sirsak (Annona muricata L.) Dengan Metode Spektrofotometri Uv-Vis. JF FIK UINAM, 3(2), pp.37-42.

4. Rismana, E. Rosidah, I., Prasetyawan ,Y., Bunga, O., Erna ,Y. (2013) 'Efektivitas Khasiat Pengobatan Luka Bakar Sediaan Gel Mengandung Fraksi Ekstrak Pegagan Berdasarkan Analisis Hidroksiprolin dan Histopatologi pada Kulit Kelinci'. Buletin Penelitian Kesehatan, 41(1), pp. 45-60.

5. Yunarto, N, dkk. 2015. 'Potensi Fraksi Etil Asetat Ekstrak Daun Gambir ( Uncaria gambir Roxb.) sebagai antihiperlipidemia'. Depok: Jurnal Kefarmasian Indonesia di Depok. Vol. 5:1-10.

6. Tursiman, Ardiningsih, P., Nofiani, R. 2012. Total Fenol Fraksi Etil Asetat Dari Buah Asam Kandis, JKK, 1(1), pp. 4548.

7. Alfian, R. dan Susanti, H. 2012. Penetapan Kadar Fenolik Total Ekstrak Metanol Kelopak Bunga Rosella Merah (Hibiscus Sabdariffa Linn) Dengan Variasi Tempat Tumbuh Secara Spektrofotometri. Makasar: Jurnal Fitofarmaka Indonesia Vol.3 No. 1 Pharmaciana

8. Syamsul, E.S., Hakim, Y.Y., Nurhasnawati, H., 2019. Penetapan Kadar Flavonoid Ekstrak Daun Kelakai (Stenochlaena palustris (Burm. F.) Bedd.) Dengan Metode Spektrofotometri Uv-Vis. 1(1), pp.11-20. 
9. Febriani, K. 2012. Uji Aktivitas Antioksidan Ekstrak dan Fraksi Daun Cocculus Orbiculatus (L.) Dc. Dengan Metode DPPH dan Identifikasi Golongan Senyawa Kimia Dari Fraksi,. Depok: Skripsi. Fakultas Matematika dan Ilmu Pengetahuan Alam Program Studi Farmasi Depok.

10. Hasanah,Nur. dan Saskiawan,I. 2015. Aktivitas Antimikroba dan Antioksidan Senyawa Polisakarida Jamur Tiram Putih (Pleurotus ostreatus): Jurnal Pros Sem Masy Biodiv Indon, Vol. 1, No. 5, Hal: 1105-1109. 